\title{
Correction
}

\section{Correction: Beckley et al., The First Alcohol Drink Triggers mTORC1-Dependent Synaptic Plasticity in Nucleus Accumbens Dopamine D1 Receptor Neuron}

In the article "The First Alcohol Drink Triggers mTORC1-Dependent Synaptic Plasticity in Nucleus Accumbens Dopamine D1 Receptor Neurons" by Jacob T. Beckley, Sophie Laguesse, Khanhky Phamluong, Nadege Morisot, Scott A. Wegner, and Dorit Ron, which appeared on pages 701-713 of the January 20, 2016 issue, the authors regret to inform the readers that mistakes in Figures representations have been identified in the article. Specifically, the representative NMDA traces of saline/D1+ in Figure $1 C$, the representative traces of miniature EPSCs of saline/D2 + in Figure $2 A$ and the representative pS6K image in Figure $6 A$ contain a mistake. In addition, the labeling of the representative images of Homer and PSD95 in Figure $8 A$ has been switched. The Figure legends, interpretation of the data, and conclusions remain the same. The raw data can be found at https://portal.g-node.org/data/. Readers can access the data by creating an account and searching for "Beckley." Below are the corrected Figures. We apologize for the errors and for creating an inconvenience for the readers.

DOI: 10.1523/JNEUROSCI.0655-16.2016

A

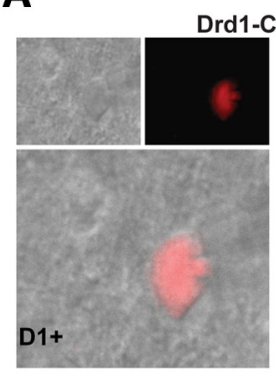

C

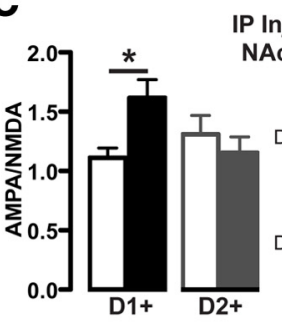

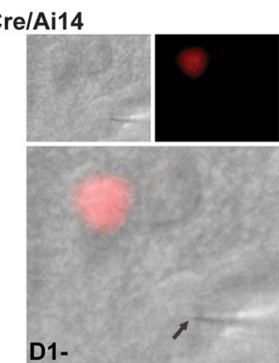

D1-

Injection

Saline<smiles>C=CC(C)C</smiles>

Alcohol

A<smiles>C1CCC2CCCCC2C1</smiles>

$2+$
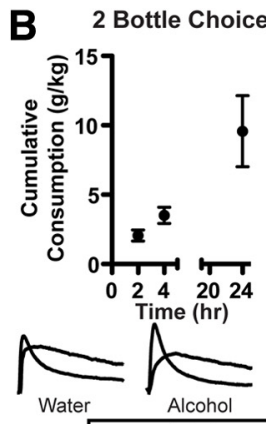

\begin{tabular}{ll} 
Water $\mathbf{Q}$ & Alcohol(2BC) $\square$ \\
\hline
\end{tabular}

IP Injection

NAc Core

Salcoho

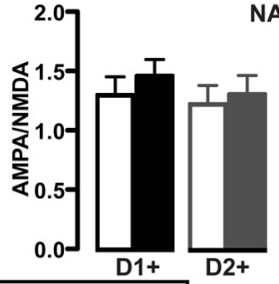

D1+

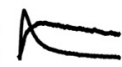

$\mathrm{D} 2+\mathrm{N}$

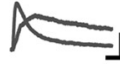

Saline $\square$ Alcohol $(2 \mathrm{~g} / \mathrm{kg}) \square$

Figure 1. 
A

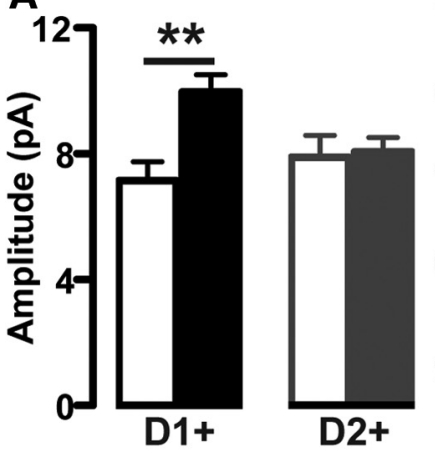

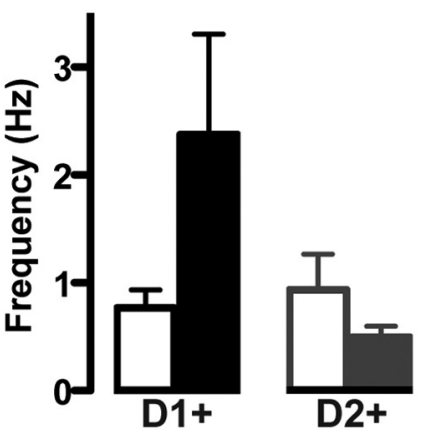

B Paired-Pulse Ratio

\section{Miniature EPSCs}

Saline

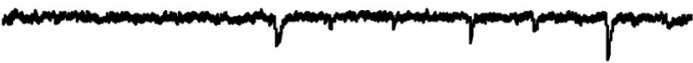

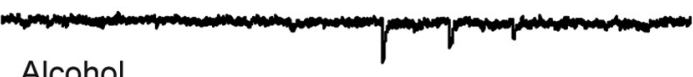

Alcohol

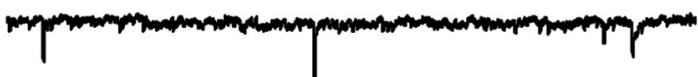

Saline
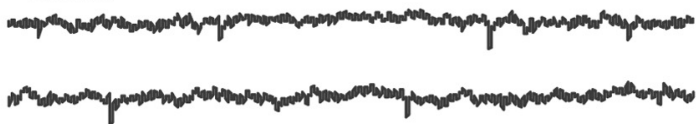

Alcohol

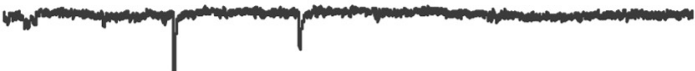

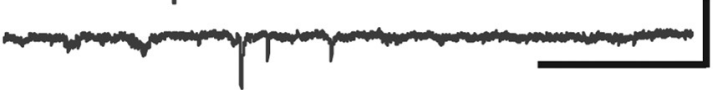

Saline $\square \mathrm{Alcohol}(2 \mathrm{~g} / \mathrm{kg})$

C

AMPA Rectification

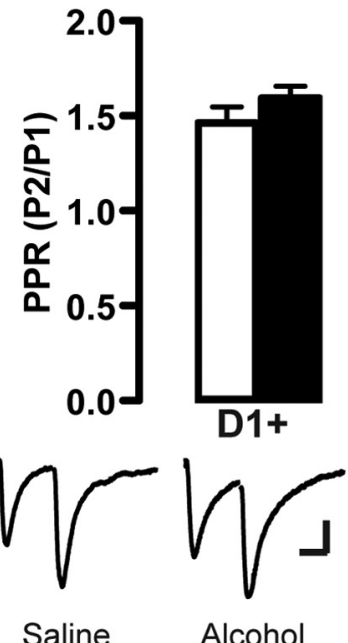

Saline Alcohol
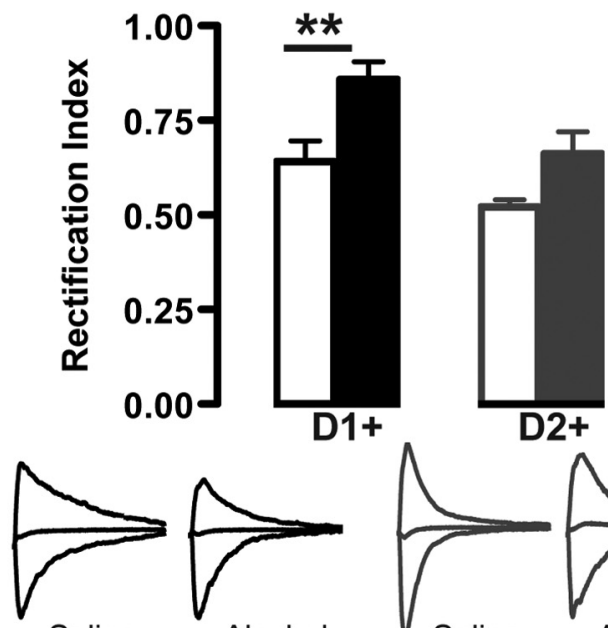

Saline

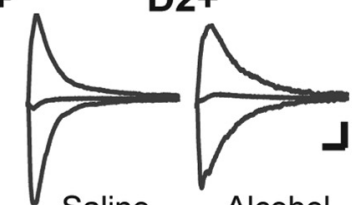

Alcohol

Figure 2. 


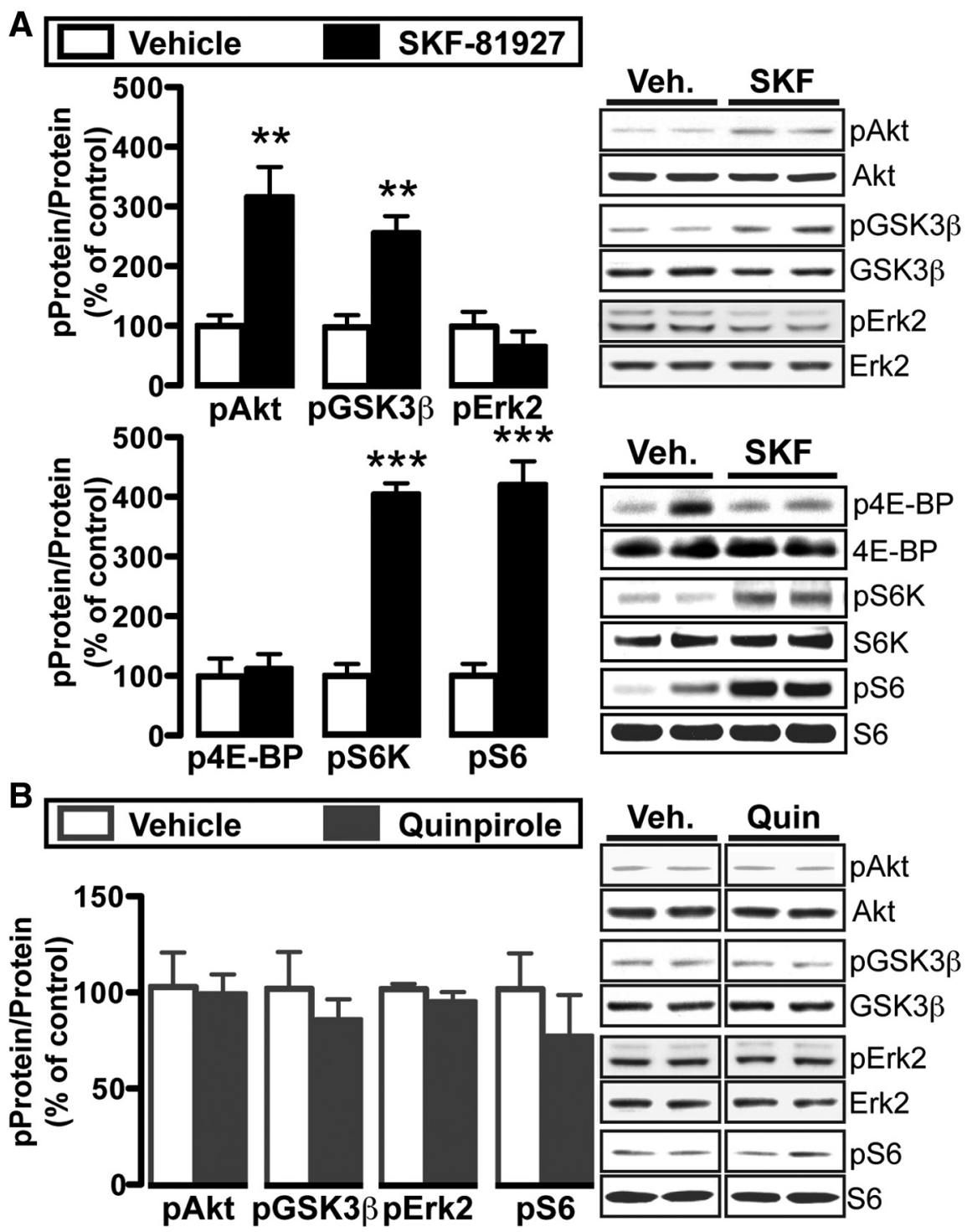

Figure 6. 
A
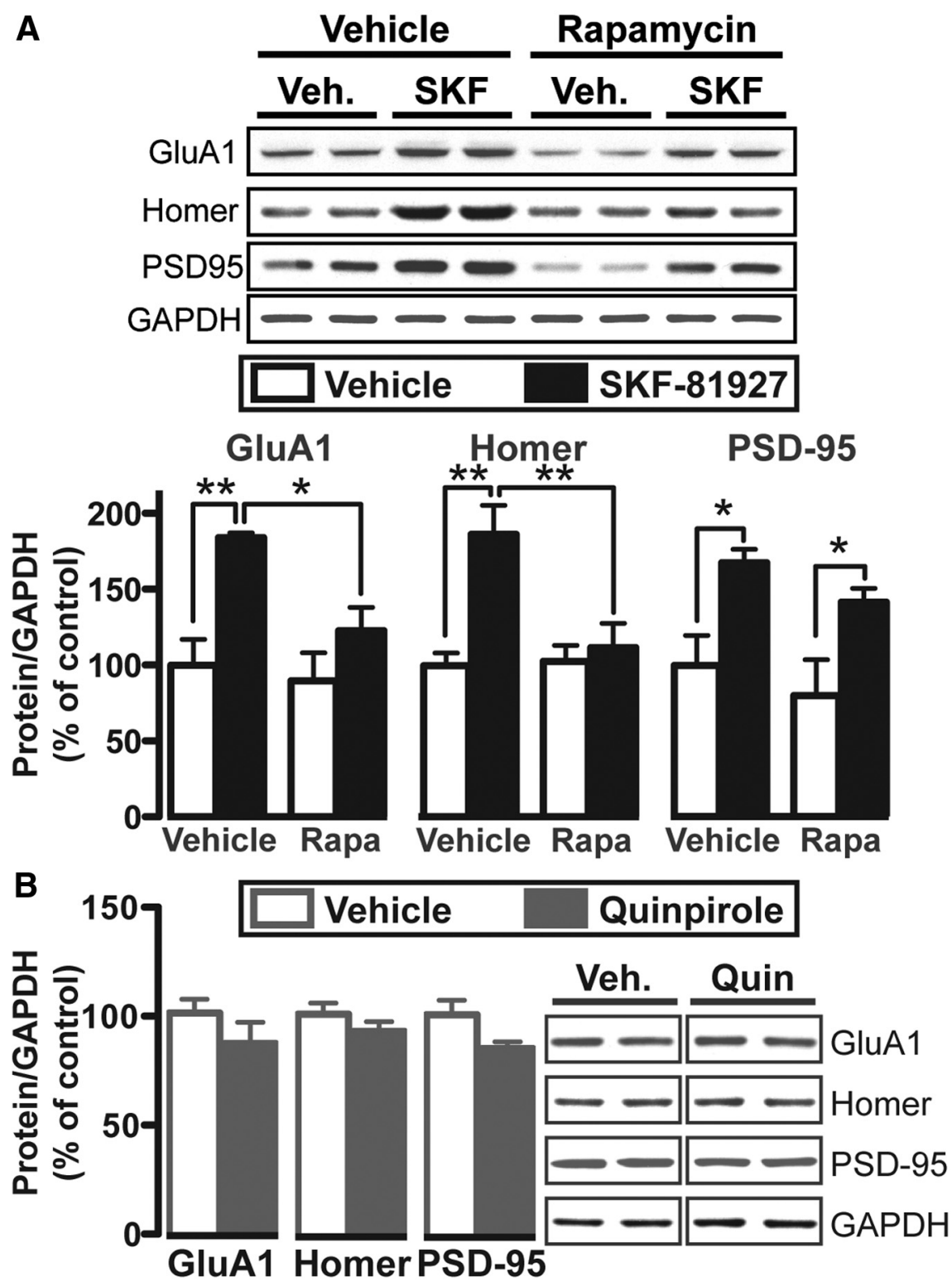

Figure 8. 